\title{
An Organisational Semiotics Perspective to Co-Design of Technology Enhanced Learning
}

\author{
Aimee Jacobs ${ }^{1}$, Yu-Chun Pan ${ }^{2}$, Sanaa Askool ${ }^{3}$ \\ ${ }^{1}$ Indiana State University, Scott College of Business, Terre Haute, Indiana, USA \\ Aimee.Jacobs@indstate.edu \\ ${ }^{2}$ University of West London, School of Computing and Engineering, London, UK \\ Yu-Chun.Pan@uwl.ac.uk \\ ${ }^{3}$ Dar Al-Hekma University, Hekma School of Business, Jeddah, Saudi Arabia \\ saskool@dah.edu.sa \\ *These authors have contributed equally to this work
}

\begin{abstract}
While Co-Design approaches have been used in designing technology enhanced learning (TEL) by different scholars, research is needed to understand the relationships between technologies, design and practice. This paper presents organisational semiotics (OS) as an approach for Co-Design of Technology Enhanced Learning. This perspective will provide an insight into the Co-Design of technology and learning in higher education.
\end{abstract}

Keywords: Technology Enhanced Learning, Co-Design. Organisational Semiotics, Learning Design, Learning and Teaching, Information Systems

\section{Introduction}

There has been a growing interest and demand in utilising technologies in an educational context to enhance learning and teaching practices [1]. Such practices are often called Technology Enhanced Learning (TEL). Some studies have shown that the use of TEL technologies has a positive impact on learning engagement and outcomes [2] [3]. However, previous research suggests that there is a disconnection between technologies, research, design and practice [4] [5], and therefore the full potential of IT/IS is not fully utilised [6].Some researchers also argue that the use of technologies does not guarantee the enhancement of learning outcomes [7].

The misalignment of IS and business requirements has resulted in a Co-Design approach. In educational context, this misalignment represents the gap between learning and teaching practices and supporting technological systems. Therefore, designing a TEL application needs to address different challenges ranging from learning theory to software engineering, which can be a key challenge for developers.

The main contribution of this paper is the organisational semiotics (OS) analysis for TEL Co-Design focusing on both technical and social aspects. The article meets this aim by discussing the current research environment for TEL and Co-Design along with the challenges, and proposes OS as a well-suited solution for Co-Design of TEL. 


\section{Context and Motivation}

\subsection{Technology Enhanced Learning}

Despite the popularity, there is no universally agreed definition of what TEL means. TEL emphasises on the learning experience of learners and the teaching experience of staff [8]. Whilst different parties have different definitions of TEL [9] [10], the various definitions all address the use and effect of technology in an educational environment. Therefore, this paper adapts other researchers' views and defines TEL as "the use and effect of any kind of IT applications in learning and teaching environment".

TEL has been increasingly adopted in educational organisations ranging from primary schools to higher education. Many researchers [9] [11] [12] [13] identify the drivers and benefits of TEL, including inclusion and diversity, stakeholder engagement, personal development, performance improvement, and innovation. It is important to consider the drivers and benefits which play a crucial role in the development and deployment of TEL applications.

\subsection{Co-Design and Technology Enhanced Learning}

The development of TEL applications has continuously attracted plenty of initiatives. The motivations behind this development include improvement of learning and teaching quality, fulfilment of learner expectations, and improvement of administrative processes [10]. Co-Design is one of the most popular participatory development methods that actively involves users for IS development [14] [15].

Co-Design has been used for the collaborative nature of designing activities that tackles the development of IS which includes the change of business requirements. Yet, existing requirements for IS development cannot be considered for Co-Design [16], as they do not consider the changing nature of requirements. Moreover, Co-Design research has been criticised by different scholars [17]. First, it is considered as "expensive" in the design process as it needs numerous meetings and discussions. Second, it is complex to deploy due to its lack of formalisation. Moreover, it focuses on the early design stage and puts few efforts on the later stages.

Current Learning theories support the importance of the social aspects in an organisational domain, however, Siemens [18] suggests that these theories lack the ability to capture the cognitive operations that are now performed by technology such as information storage and retrieval that were previously performed by learners. This indicates the disconnection between learning and teaching practice and supporting technological systems. Educational organisations should emphasise the quality of the technology use and the way it supports achieving learning objectives, rather than only the use of technology [19].

Based on these challenges, OS methods could improve the understanding of the requirements for TEL design. Additionally, OS provides a framework to bridge the gap left by current learning theories and the social aspects of technology. The following section introduces OS and the OS methodologies used as a framework. 


\section{Theoretical Background: Organisational Semiotics}

OS is the study of organisations using concepts of semiotics [20]. OS is positioned to meet the needs of both the technical and social aspects in an organisational domain [21]. These aspects make it well suited to meet the needs lacking in current design and theories for TEL. OS is first introduced by Stamper [22] based on Peirce [23]'s work on semiotics. Signs are formulated through a sign mediation process known as semiosis [24]. OS has been applied in various domains, e.g. IS design [25], knowledge management [26], and social media readiness assessment [27].

The OS perspective, which concentrates on the relations between the IT system, and organisation, offers a range of methods to analyse and design organisations [20]. The OS framework, also known as the semiotic ladder, supports the view of inseparability of technical and social aspects of an organisation (or an information system) through the use of the six branches of semiotics diagnosis [20]. This framework aids in classifying signs within the multi-layers of an organisation from the two views of human information functions and IT platform. The OS framework allows an investigation into the human as well as the technological aspects of TEL, as many researchers [18] [28] suggest it is necessary to capture the learning process as well as the social and contextual factors and the value of what is being learned through technology. The following section provides the OS analysis for TEL Co-Design.

\section{Organisational Semiotic Perspective to TEL Co-Design}

The current TEL design approach focuses on how to create technologies to support learning and teaching environment. As previously discussed, there are two major issues in this approach. Firstly, technologies and human behaviours have the capabilities to influence and shape each other. Secondly, whilst Co-Design method has been applied to TEL application development, the current level and scope of user involvement might not necessarily be sufficient, as there are more participants than teachers and learners. This research addresses these two issues by applying OS to further analyse the activities in educational environment where technologies are used.

\subsection{Learning System and Technical System in TEL Environment}

In order to fully understand the relationship between human agents and technologies in TEL environment, this paper establishes the definitions of informal and formal learning system and technical system. Informal and formal learning systems refer to the culture, structure, process, people and information in learning and teaching environment. It includes all the human activities, controlled by either formal or informal norms, performed by participants in order to achieve the learning objectives. On the other hand, technical system refers to the IS that supports and enhances the operations of learning systems. As shown in Fig. 1, technical system is part of informal and formal learning system. Human participants utilise the data and information stored and processed in the technical system in order to perform in learning system. Through the lens of OS, the 
environment can be considered as a meta-system including all the six layers of the semiotic ladder.

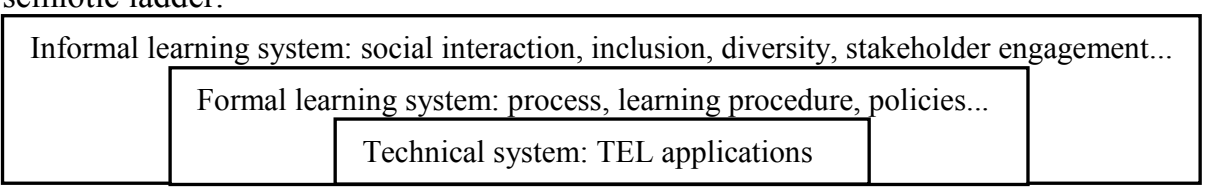

Fig. 1: Informal and Formal Learning System and Technical System

\subsection{Organisational Semiotics Analysis for TEL Co-Design}

Co-Design emphasises community and research as part of the participatory process. It focuses on participant involvement, perceptions and the feedback loop. Developers have created the co-design processes based on their need to obtain users' new ideas and feedback, however, the user feedback will be designed from users' perspective. The attractiveness of OS viewpoint for CO-Design is that it can offer analysis of the community interlinks to technology. OS offers a systematic way to analyse the deisgn requirements including what is being designed, purpose of the design, resources needed, and mechanisms required to foster communication among the community. It also helps identify the activities around the students and instructors, which helps identify participant roles within the design process.

The OS analysis of the TEL environment can be categorised into six distinctive layers (see Fig. 2). The analysis of the learning system and technical system identified the requirements for TEL in the human information functions and the IT platform respectively. This analysis of TEL may provide the foundation for TEL Co-Design.

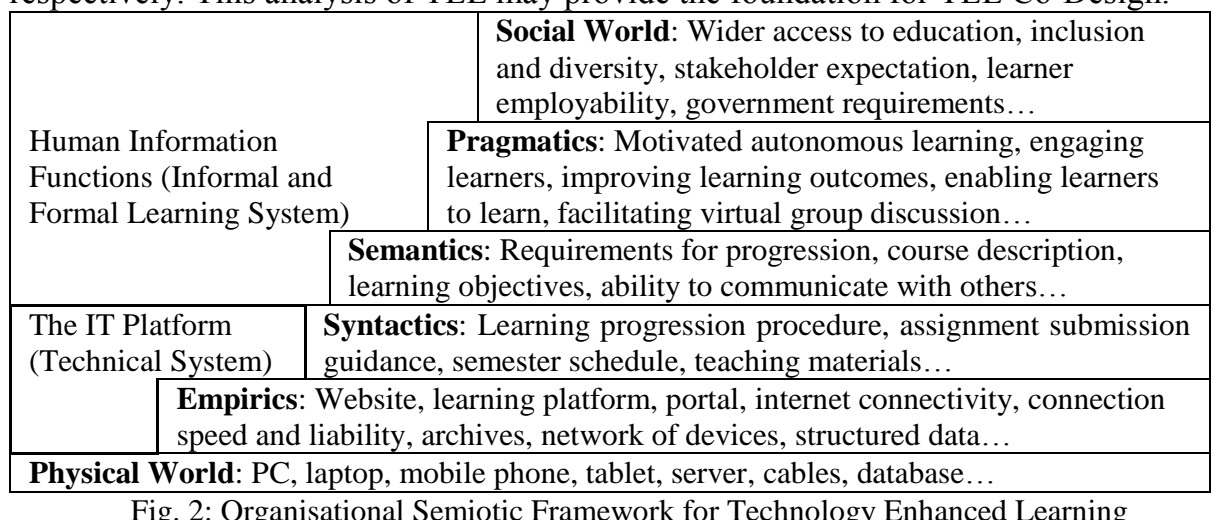

\section{Discussion and Conclusion}

TEL changes how learning and teaching processes can be managed and delivered. However, the use of IT/IS to enhance learning can lead to some challenges in the communication and interaction process between students and instructors. Moreover, using technology to enhance learning creates a lack of ownership of design, because 
participants with diverse responsibilities and tasks influence the common paradigm in the classroom. This could be due to a lack of requirements engineering methods that could reflect negatively on the system's analysis and design.

The use of technology and its effects in the educational context has prompted significant interest in the development of TEL applications. However, there is a gap between learning system (learning and teaching practice) and technical system (TEL applications), as many TEL developments fail to recognise learning system and technical system as one integral unit. Co-Design approach has also been deployed in the development of TEL applications. However, Co-Design itself presents challenges, as it is expensive and lacks formality for users to follow. Considering these challenges, OS can be considered a suitable perspective to investigate the TEL environment and its application development because it concerns both social and technical aspects of IT/IS.

By applying OS perspective, the OS framework analysis for TEL provides a comprehensive insight into the key requirements for TEL Co-Design. The analysis identifies the interlinked requirements at the six OS layers. The requirements at higher layers need to be supported by the requirements at lower layers for the IT platform to support the human activities. The understanding of how requirements at different OS layers support each other could allow TEL requirements to be analysed in this manner. Furthermore, Co-Design requires the collective effort of participants at various levels in order to maximise the effectiveness of the design product.

A limitation, however, is that the research framework is based on literature review without empirical studies. However, the proposed demonstrates the relationships between technologies, design and practice which will allow greater integration of technical system into the process of learning system and it is expected to offer guidelines for analysing TEL solutions. Further research can be applied to a case study of an organisation in higher education.

In summary, this paper focused on the improvement of TEL grounded in OS as it applies to both higher education as an organisation and TEL. The analysis highlights TEL requirements through the six layers in OS framework focusing on semantic, pragmatic and social aspects of teaching and learning without ignoring the technical aspects. OS could foster researchers and practitioners understanding of the systems requirements by driving the analysis and Co-design of TEL tools.

\section{Reference}

1. Selwyn, N.: The use of computer technology in university teaching and learning: a critical perspective. Journal of computer assisted learning, vol. 23, no. 2 (2007) 83-94

2. Shieh, R. S.: The impact of Technology-Enabled Active Learning (TEAL) implementation on student learning and teachers' teaching in a high school context. Computers \& Education, vol. 59, no. 2 (2012) 206-214

3. Shieh, R., Chang, W. and Liu, Z.: Technology enabled active learning (TEAL) in introductory physics: impact on genders and achievement levels. Australian Journal of Educational Technology, vol. 27, no. 7, (2011) 1082-1099

4. Hannafin, W. a.: Design-based research and technology-enhanced learning environments. Educational Technology Research and Development, vol. 53, no. 4 (2005)

5. Keppell, M.: Assuring best practice in technology-enhanced learning environments. Research in Learning Technology, vol. 23 (2015) 
6. Manca, S. and Ranieri,M.: Is it a tool suitable for learning? A critical review of the literature on Facebook as a technology-enhanced learning environment. Journal of Computer Assisted Learning, vol. 29, no. 6 (2013) 487-504

7. Fewkesa, A. M. and McCabea, M.: Facebook: Learning tool or distraction?. Journal of Digital Learning in Teacher Education, vol. 28, no. 3 (2012) 92-98

8. University of the West of England: Technology Enhanced Learning Strategy and Implementation Plan 2012-2017. University of the West of England, Bristol (2012)

9. HEFCE: Enhancing learning and teaching through the use of technology: a revised approach to HEFCE's strategy for e-learning. HEFCE, Bristol (2009)

10. Walker, R., Voce, J., Nicholls, J., Swift, E., Ahmed, J., Horrigan, S. and Vincent, P.: 2014 Survey of Technology Enhanced Learning for higher education in the UK. Universities and Colleges Information Systems Association, Oxford, UK (2014)

11. Quentin-Baxter, M., Kelly, J., Probert, S., MacMahon, C. and Ferrell, G.: A model for evidencing the benefits of technology enhanced learning in higher education in the UK. Proceedings of ASCILITE (2008)

12. Keller, J. and Suzuki, K.: Learner motivation and e-learning design: A multinationally validated process. Journal of educational Media, vol. 29, no. 3, (2004) 229-239

13. Law, K. M., Lee, V. C. and Yu, T.: Learning motivation in e-learning facilitated computer programming courses. Computers \& Education, vol. 55, no. 1 (2010) 218-228

14. Steen, M.: Human-centered design as a fragile encounter. Design Issues, vol. 28 , no. 1 (2012) 72-80

15. Sanders, E. and Stappers, P.: Co-creation and the new landscapes of design. Co-Design, vol. 4, no. 1 (2008) 5-18

16. Liu, K., Sun, L. and Bennett, K.: Co-Design of Business and IT Systems - Introduction by Guest Editors. Information Systems Frontiers, vol. 4, no. 3 (2002) 251-257

17. Tollmar, K.: Towards CSCW design in the Scandinavian tradition, Stockholm, Sweden: Tekniska högsk (2001)

18. Siemens, G.: Connectivism: A learning theory for the digital age. (2014)

19. Marshall, S.: Change, Technology and Higher Education: Are Universities Capable of Organisational Change. Journal of Asynchronous Learning Networks, vol.15 (2011) 22-34

20. Liu, K.: Semiotics in Information System Engineering, Cambridge University Press (2000)

21. Liu, K.: Virtual, Distributed and Flexible Organisations, Springer (2004)

22. Stamper, R.: Information in Business and Administrative Systems, NY: Wiley (1973)

23. Peirce, C. S.: Collected papers of Charles Sanders Peirce: Pragmaticisms and pragnoaticism and scientific metaphysics, MA, USA: Belknap Press (1935)

24. Nauta, D.:The Meaning of Information, Hague: Mouton (1972)

25. Stamper, R., Liu, K., Hafkamp, M. and Ades, Y.: Understanding the roles of signs and norms in organizations-a semiotic approach to information systems design. Behaviour \& Information Technology. vol. 19, no. 1 (2000) 15-27

26. Pan, Y. and Tan, C.: Three Dimensional Norm-Based Knowledge Management for Knowledge Intensive Business Service Organizations: An Organizational Semiotics Perspective. International Journal of Knowledge Engineering, vol. 2, no. 1 (2016) 50-55

27. Jacobs, A.: Assessing Organisational Readiness for Enterprise Social Media in Information Intensive Organisations, PhD Thesis, University of Reading, Reading UK (2013)

28. Chen, Y., Lin, Y., Yeh, R. and Lou, S.: Examining factors affecting college students' intention to use web-based instruction systems: towards an integrated model. Turkish Online Journal of Educational Technology, vol. 12, no. 2 (2013) 111-121 